\title{
定速回転制御系における角度依存性外乱 の新しい除去法
}

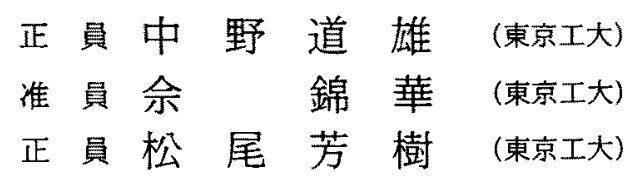

\section{A New Approach to Reject Angle Dependent Disturbances in Constant Speed Rotation Control Systems}

Michio Nakano, Member, Jin-Hua She, Associate, Yoshiki Matsuo, Member(Tokyo Institute of Technology)

High precision and good command response are the most important requirements in performance of constant speed rotation control systems. It is the rotational speed fluctuations caused frequent by rotational angle dependent disturbances that have hindered all efforts to improve the precision of such systems.

This paper proposes a new approach focusing on the fact that this kind of disturbance constitutes cyclic function of the rotational angle. The proposed design is set in the 'angle domain' instead of the 'time domain' so as to eliminate such disturbances completely without regard to the rotational speed.

The results of the simulation reported in this paper will prove that the constant speed rotation control system designed according to the proposed approach removes all rotational speed fluctuations apart from speed setting changes.

キーワード：定速回転系，角度依存性外乱，二自由度制卸系，絽返し制御， $\boldsymbol{H}_{\infty}$ 制御，デッドビート制御

\section{1.まえがき}

定速回転系では，回転速度が目標とする設定值に高 精度かつ高速に追従することが要求される。しかし一 般に, 回転系ては, 回転角度に依存した外乱による回 転むらが発生し, 回転系の精度向上を大きく妨げるこ

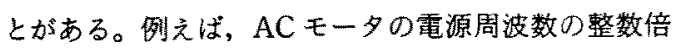
で変動するトルク成分, DCモー夕の界磁の不均一 性, 電機子のコギングおよびロー夕系の偏心, 軸のガ タなどに起因する速度変動はその例である。

この種の外乱の除去について, 従来は, 回転系の機 構的な改善手法を用いたり ${ }^{(1)}$ ，時間領域でこの問題を とらえたり(2)してきた。特に，時間領域ての角度依 存性外乱の除去法では，まず定速回転時を想定し，角
度依存性外乱を回転に同期した一定周期の時間周期関 数と考え，時間領域での緑返しコントローラを用いて いた。しかし，前者の方法では，この種の外乱の除去 効果は必ずしも十分とはいえず，後者の方法では，所 定の回転速度に対する除去効果は良いが，回転速度の 設定值が変化した場合，除去効果が劣化するという問 題点が指摘されている。

本論文では,この種の外乱が回転角度の周期関数と なるという特徵に注目し，時間領域の代わりに「角度 領域」でコントローラを設計することにより，この種 の外乱を回転速度と関係なく完全に除去する高精度な 回転制御系を構成する手法を提案する。更に，本手法 を用いることによって，設定值変化と無関俰に回転系 の回転むらが完全に除去できることをシミュレーショ 
ンにより㕰政する。

ただし，本方式ていう「角度領域」とは，回転角度 上で定義された関数の集合である。

なお，本論文では次の数学記号を用いる。

$\lambda:$ 幄延作用掌 $\left(=z^{-1}\right)$

$R H_{\infty}$ : 複菜数平面上の閉単位円領域に極をも

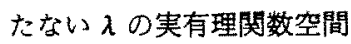

$\boldsymbol{R}(\lambda): \lambda の$ 奏数多項式環 $\left(\subset \boldsymbol{R} \boldsymbol{H}_{\infty}\right)$

$\|G(\lambda)\|_{\infty}:=\sup _{0 \leq \phi \leq 2 \pi}\left|G\left(e^{j \phi}\right)\right| \quad\left[G(\lambda) \in \boldsymbol{R} \boldsymbol{H}_{\infty}\right]$

$a_{+}(\lambda)$ : 複素数平面上の閉筆位円領域に雾点を もつ生ニックな多項式

$a$ - $(\lambda)$ : 複素数平面上の閉単位円領域を除く領 域に雾点を虽つ多項式

\section{2. 角度領域における定速回転系の記述}

2 入力, 1 出力， $n$ 次の可制御，可観測な回転系 時間領域における状態表現は次式によって与えられて いるとする。

$$
\begin{aligned}
& \left.\begin{array}{l}
\frac{d x(t)}{d t}=A x(t)+B\left[u_{p}(t), v(t)\right]^{T} \\
\omega(t)=\Psi_{x}(t)+\Gamma\left[u_{p}(t), v(t)\right]^{T}
\end{array}\right\} \cdots \cdots(1) \\
& \text { ただし, } u_{p}(t): \text { 制御入力, } v(t): \text { 外乱（角 }
\end{aligned}
$$

度に関して周期性をもつ)， $\omega(t)$ : 回転速度

角度領域における回転系の数学モデルを求める際, まず時間領域から角度領域八変換可能なためには, 以 下の変换条件が要求される。

〈变換集件〉時間領域から角度領域へ変換できるた めの必要十分条件は任意の時点において，回轻方向は 変わらないことである。すなわち，もし実際の回転方 向を回転の正方向とすると，次式のように表される。

$$
\omega(t)=\frac{d \theta}{d t}>0 ; \quad \forall t>0
$$

(2) 式は回転角度 $\theta=\theta(t)$ の逆関数 $t:=t(\theta)$ の存 在条件を示している。

以下では，上の変換条件が常に满たされているとす る。このとき, 時間領域における変数と角度領域にお ける変数の間には以下のような関係が成立する。

$$
\begin{aligned}
& \begin{aligned}
& t=t(\theta) \\
& {\left[u_{p}, \nu\right]^{T} }=\left[u_{p}(t), \nu(t)\right]^{T} \\
&=\left[u_{p}\{t(\theta)\}, \nu\{t(\theta)\}\right]^{T} \\
&=\left[\tilde{u}_{p}(\theta), \tilde{v}(\theta)\right]^{T} \\
& \omega=\omega(t)=\omega\{t(\theta)\}:=\tilde{\omega}(\theta) \\
& x=x(t)=x\{t(\theta)\}:=\bar{x}(\theta) \\
& \frac{d x}{d t}=\frac{d \tilde{x}}{d \theta} \frac{d \theta}{d t}=\tilde{\omega}(\theta) \frac{d \tilde{x}(\theta)}{d \theta}
\end{aligned}
\end{aligned}
$$

以上の㚆奐によって，特に角度依存性外乱 $\tilde{\nu}(\theta)$ は 回転角度 $\theta$ に関して基本周期 $T=2 \pi(\mathrm{rad}) の$ 周期成 数となるため，角度領域における綵返しコントローラ を用いることによって，ての影響が完全に除去できる はずである(3)。

（3）式を(1)式に代入すると，角度領域における回 転系の数学モデルは

$$
\left.\begin{array}{l}
\tilde{\omega}(\theta) \frac{d \bar{x}(\theta)}{d \theta}=A \tilde{x}(\theta)+B\left[\tilde{u}_{p}(\theta), \tilde{v}(\theta)\right]^{T} \\
\tilde{\omega}(\theta)=\Psi \bar{x}(\theta)+\Gamma\left[\tilde{u}_{p}(\theta), \tilde{v}(\theta)\right]^{T}
\end{array}\right\}
$$

\section{と求められる。}

角度領域における回転系の数学モデル(4)式は非線 形である。線形システム制衘理論を用いて制御系を設 副するために，非線形モデル(4) 式を平衡点

$(\bar{\omega}(\theta), d \bar{x}(\theta) / d \theta]=(\bar{\omega}, 0) の ま わ り て$ 線形近似を行 う。その結果, その線形モデルは

$$
\left.\begin{array}{l}
\frac{d \tilde{x}(\theta)}{d \theta}=\tilde{A} \tilde{x}(\theta)+\bar{B}\left[\tilde{u}_{p}(\theta), \tilde{v}(\theta)\right]^{T} \\
\tilde{\omega}(\theta)=\tilde{\Psi} \tilde{x}(\theta)+\tilde{\Gamma}\left[\tilde{u}_{p}(\theta), \tilde{v}(\theta)\right]^{T}
\end{array}\right\}
$$

と求められる。ただしここで

$$
\bar{A}=\frac{A}{\tilde{\omega}_{\tau}} ; \quad \tilde{B}=\frac{B}{\tilde{\omega}_{r}} ; \quad \tilde{\Psi}=\Psi ; \quad \tilde{\Gamma}=\Gamma ;
$$

でる。

ここで求めた線形モデルのパラメータ（6)式は平衡 点における回転速度の值 $\tilde{\omega}_{r} に$ 依存しているため, 動 作点の変化により制御対象の特性の変動をもたらし,

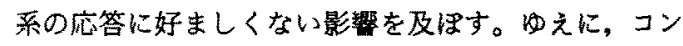
トローラを設計する際，制御対象の特性変動の影響を 十分に抑制しなければならない。

\section{3. 定速回転制御系の構成およびコントローラ の設計}

〈3.1〉定速回転制御系の構成本制御系の設計 にあたり

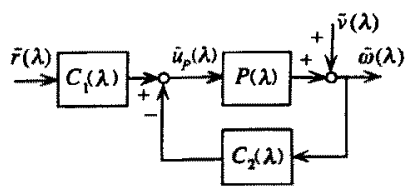

图 1 定速回転制御系 $\left(\lambda=z^{-1}\right)$

Fig. 1. Configuration of the constant speed rotation control system. 
（1）角度依存性外乱の除去

（2）設定值変化に対する良好な過渡特性

（3）制御対象の特性変動による影整の抑制

とにう要求を韁たすたかに，定速回転制御系は，角度 領域における平衡点のまわりでの回転系の線形近似モ デル（5)式を用いて，図1のような二自由度制御系を

構成した。

ここでは $P(\lambda)$ を角度領域での制御対象のパルス伝 達関数とし, $C(\lambda)=\left[C_{1}(\lambda), C_{2}(\lambda)\right]$ を角度領域てのコ ントローラとする。

〈3・2〉コントローラの設㖕法 （5）式の線形近 似モデルの出力は一定角度でサンプリングされる。そ のため，その入力に角度に関してのぜロ次ホールドを 置く。雕散化した制御対象のパルス伝達関数を $P(\lambda)$ とし， $P(\lambda)$ は単位円上には極，零点をもたないもの とする。

$P(\lambda)$ の既約分解を

$$
P(\lambda)=\frac{N(\lambda)}{D(\lambda)} ; N, D \in R[\lambda]
$$

とすると，Bezout 方程式

$$
X N+Y D=1
$$

を満たす $X, Y \in R(\lambda)$ が存在し, 図 1 の系を内部安定 化するコントローラ $C=\left[C_{1}, C_{2}\right]$ の一般形は

$$
\begin{array}{r}
C=\left[C_{1}, C_{2}\right]=\left(Y-K_{2} N\right)^{-1}\left[K_{1}, X+K_{2} D\right] \\
K_{1}, K_{2} \in R H_{\infty} \ldots \ldots \ldots \ldots \ldots \ldots \ldots \ldots(9
\end{array}
$$

と表せる(い)(5)。

定常状態において，角度依存性外乱の影響を完全に 除去するためには繰返しコントローラが制御系のコン トローラ $C=\left[C_{1}, C_{2}\right]$ に含まれていなければならな い。すなわち，コントローラ $C=\left[C_{1}, C_{2}\right]$ の氷母 $(Y$ $\left.-K_{2} N\right)$ には因子 $\left(1-\lambda^{2}\right)(L:$ 䋩返しコントローラの 段数)が含まれていなければならない。

$$
\begin{aligned}
& \text { そこて, } \\
& Y:=\left(1-\lambda^{L}\right) Y^{\prime} ; Y^{\prime} \in R[\lambda]
\end{aligned}
$$$$
K_{2}:=\left(1-\lambda^{L}\right) K_{2}^{\prime} ; K_{2}^{\prime} \in R H_{\infty}
$$

とおくと，(8)式の代わりに次の方程式

$$
X N+\left(1-\lambda^{2}\right) Y^{\prime} D=1
$$

を满たす $X, Y^{\prime} \in R(\lambda)$ を求めればよい。単位円上に 零点をもたない $N$ と $\left(1-\lambda^{L}\right) D$ とが既約であること より，(12)式を蠆たす $X, Y^{\prime} \in R[\lambda]$ が存在する。この とき, コントローラ $C=\left[C_{1}, C_{2}\right]$ の分母 $\left(Y-K_{2} N\right)$ は

$$
\left(1-\lambda^{2}\right)^{-1}\left(Y-K_{2} N\right) \in R H_{\infty}
$$

を満たす。明らかに（13)式は定常状態における角度 依存性外乱の完全除去のための条件である ${ }^{(6)} 。$ 従っ て， $Y^{\prime}$ と $X$ は (12)式を满たすように選び， $Y は$

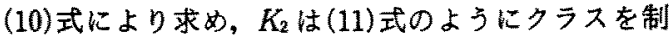
限すればよい。

以上のことをまとめると，コントローラ $C=\left[C_{1}\right.$,

$C_{2}$ ] 壮次式で表すことがでる。

$$
\begin{aligned}
C= & {\left[C_{1}, C_{2}\right] } \\
= & \left(1-\lambda^{L}\right)^{-1}\left(Y^{\prime}-K_{2}^{\prime} N\right)^{-1} \\
& \times\left[K_{1}, X+\left(1-\lambda^{2}\right) K_{2}^{\prime} D\right] \\
& \quad K_{1}, K_{2}^{\prime} \in R H_{\infty} \cdots \cdots .
\end{aligned}
$$

このとさ，系の諸特性は以下のようになる。

$$
\begin{gathered}
\tilde{r} \rightarrow \tilde{\omega}: \frac{P C_{1}}{1+P C_{2}}=N K_{1} \ldots \ldots \ldots \ldots \ldots \ldots . . . . . . . \\
\tilde{\nu} \rightarrow \tilde{\omega}: \frac{1}{1+P C_{2}}=\left(1-\lambda^{2}\right) D\left(Y^{\prime}-K_{2}^{z} N\right)
\end{gathered}
$$

明らかに，外乱から回転速度までのパルス伝達特性

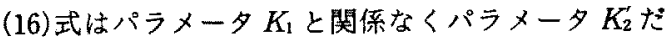
けに依存している。そのため，角度依存性外乱の抑制 という要求はパラメータK $K_{2}^{\prime}$ を適切に選ぶことによつ て実現できる。た，系の入出力特性(15)式はパラメ

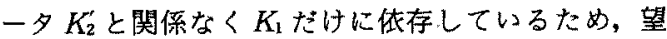
みの入出力特性という要求はパラメー夕 $K_{1}$ を適切に 選ぶことによって夷現できる。

（1）パラメー夕K光の決定法 角度依存性外乱 の出力に対する影熼は

$$
\bar{\omega}_{\tilde{\nu}}=\frac{1}{1+P C_{2}} \tilde{\nu}=S \tilde{\nu}
$$

で表すことができ，ここで制御系の感度は，

$$
S=\frac{1}{1+P C_{2}}
$$

である。外乱の出力に対する影䋨を低く抑制するため に, 重み付け感度の $H_{\infty}$ ノルム $\left\|\left(1-\lambda^{L}\right)^{-1} S\right\|_{\infty}$ を最小 にすることが望まれる。

また，回転速度が目標設定値であるときの回転系の 伝達関数を $P(\lambda)$ とし, 設定值が変化したときの回転 系の伝達関数を $\hat{P}(\lambda)$ とすると, 基準目標值の場合と 設定值変化後の場合の系の入出力特性はそれぞれ

$$
\begin{aligned}
& G_{\bar{r} \bar{\omega}}=\frac{P C_{1}}{1+P C_{2}} \\
& \hat{G}_{\bar{r} \bar{\omega}}=\frac{\bar{P} C_{1}}{1+\bar{P} C_{2}}
\end{aligned}
$$

となる。本制御系において，問題となる動作点の変動 による系の入出力特性の㚆動は

$$
\frac{\hat{G}_{\tilde{r} \bar{\omega}-G_{\bar{r} \bar{\omega}}}}{\bar{G}_{\bar{r} \bar{\omega}}}=\frac{1}{1+P C_{2}} \frac{\hat{P}-P}{\hat{P}}=S \frac{\hat{P}-P}{\hat{P}}
$$

と表すことがで、制御対象の特性変動の影裂を受け 
にくい制御系を構成するのは,やはり制御系の感度 $S$ を低く抑えなければならないことがわかる。

そこで,以下のような評価関数

$$
J_{2}=\left\|\frac{1}{1-\lambda^{L}} S\right\|=\left\|D\left(Y^{\prime}-K_{2}^{\prime} N\right)\right\|_{\infty}
$$

を考える。 $\inf _{K_{2} \in R H_{\infty}} J_{2}$ を達成するように $K_{2}^{\prime}$ を决めるこ とによって，外乱の影響が抑制され，しかも低周波領 域に抬ける入出力特性変動も抑制されている。この $H_{\infty}$ 制御問題は

$$
T_{1}=D Y^{\prime} ; T_{2}=D ; T_{3}=N
$$

とおけば，標準的なモデルマッチング間題に㷌着て き，本問題において $T_{2}$ と $T_{3}$ は単位円上に零点をもた

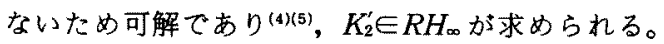

（2）パラメータ $K_{1}$ の決定法 ステップ状の回 転速度の設定值変化に対し出力の回転速度が高速応答

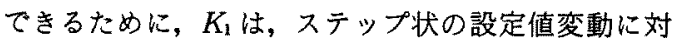
し出力が有限整定し, しが告整定するまでの出力誤差 および制御入力を小さく㧕えるように決める(7)。

ここで, 制御対象を

$$
P(\lambda)=\frac{\lambda^{m} b(\lambda)}{a(\lambda)}=\lambda^{m} \frac{b_{0}+b_{1} \lambda+\cdots+b_{1} \lambda^{l}}{a_{0}+a_{1} \lambda+\cdots+a_{n} \lambda^{n}}
$$

$a_{0}, b_{0} \neq 0 ; a(\lambda), b(\lambda):$ 互いに素

とすると，前節における $N, D$ はそれぞれ

$$
N(\lambda)=\lambda^{m} b(\lambda) ; D(\lambda)=a(\lambda)
$$

となる。(24)式において, $a(\lambda)$ と $b(\lambda)$ を

$$
\left.\begin{array}{l}
a(\lambda)=a_{-}(\lambda) a_{+}(\lambda) \\
b(\lambda)=b_{-}(\lambda) b_{+}(\lambda)
\end{array}\right\}
$$

と分解し，更に入出力誤差を

$$
\bar{e}(\lambda):=\tilde{r}-\tilde{\omega}=\frac{1-N K_{1}}{1-\lambda}=\sum_{i=0}^{\mu} \tilde{e}_{i} \lambda^{i}
$$

とすると，Klに課されているデッドビート性をもつ ための制約条件は以下のようである(7)。

ステップ状の設定值変化に対して, 出力が有限整定 となる $K_{1} \in R H_{\infty}$ が存在するための必要十分条件は， 適切な多項式 $f(\lambda) \in R[\lambda]$ が存在し,

$$
1-(1-\lambda)\left(\sum_{i=0}^{\mu} \tilde{e}_{i} \lambda^{i}\right)=\lambda^{m} b_{+}(\lambda) f(\lambda)
$$

が満たされることである。

$f(\lambda)$ は, 制約 (28) 式のもとで, 次の評価関数

$$
\begin{aligned}
& J_{1}=\sum_{i=0}^{\infty}\left(\left|\bar{e}_{i}\right|^{2}+\rho^{2}\left|\Delta \tilde{u}_{i}\right|^{2}\right) \\
& \sum_{i=0}^{\infty} \Delta \bar{u}_{i} \lambda^{i}=(1-\lambda) \bar{u}(\lambda)
\end{aligned}
$$$$
\rho: \text { 重み係数 }
$$

を最小にするように定め， $K_{1}$ を決定すると，

$$
K_{1}(\lambda)=\frac{f(\lambda)}{b_{-}(\lambda)}
$$

となる。

\section{4. シミュレーション}

まず，時間領域における回転系は

$$
J \frac{d \omega}{d t}+D \omega=B u_{p}+\nu
$$

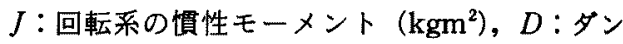
ピング係数 $(\mathrm{Nms} / \mathrm{rad}), B$ : 入力係数 $(\mathrm{Nm} / \mathrm{V})$ と し,そのパラメータは

$$
J=0.1 ; D=1 ; B=1
$$

とし，その基準目標速度 $\omega_{r}$ を

$$
\omega_{r}=20 \mathrm{rad} / \mathrm{s}
$$

とする。

入力が目標設定值のときの角度領域における制御対 象の伝澾関数を求め，サンプリング・インターバル

$$
\Delta \theta=0.174533 \mathrm{rad}(=10 \mathrm{deg})
$$

で離散化すると, 制御対象のパルス伝達関数のノミナ ル値は

$$
\begin{aligned}
& P(\lambda)=\frac{\beta \lambda}{\lambda-\alpha} \\
& \alpha=1.091187 ; \beta=-0.091187
\end{aligned}
$$

となる。

角度依存性外乱は, 角度領域において, 基本周期 $T=2 \pi(\mathrm{rad})$ の周期関数となるので, 繰返しコントロ ーラの段数は

$$
L=T / \Delta \theta=2 \pi / \Delta \theta=36
$$

である。(35)式に対し，上で提案した設計法でコント ローラを設計する。

まず，制御対象の伝達関数について

$$
P(\lambda)=\frac{N(\lambda)}{D(\lambda)}=\frac{\lambda^{m} b(\lambda)}{a(\lambda)}
$$

と分解すると

$\left.\begin{array}{l}D(\lambda)=\lambda-\alpha ; N(\lambda)=\beta \lambda \\ a(\lambda)=a_{0}+a_{1} \lambda=-\alpha+\lambda ; b(\lambda)=b_{0}=\beta ; m=1\end{array}\right\}$

となる。更に， $a(\lambda)$ と $b(\lambda)$ を(26)式のように分解す ると, 次のようになる。

$$
\left.\begin{array}{l}
a_{-}(\lambda)=-\alpha+\lambda ; a_{+}(\lambda)=1 \\
b_{-}(\lambda)=\beta ; b_{+}(\lambda)=1
\end{array}\right\}
$$

方程式 (12)式を解くと,

$$
X=\frac{1+\alpha \lambda^{L-1}-\lambda^{L}}{\alpha \beta} ; Y^{\prime}=-\frac{1}{\alpha}
$$




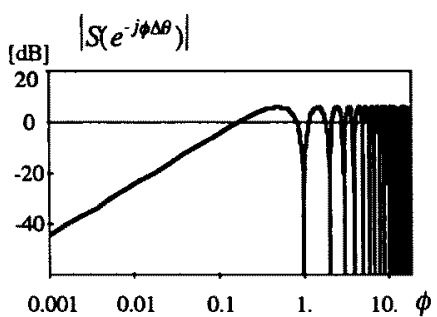

図 2 系の感度特性

Fig. 2. Sensitivity characteristic of the designed system.

となり，パラメータ $K_{2}^{\prime}$ を求めると,

$$
K_{2}^{\prime}=-\frac{1}{\alpha \beta(\lambda-\alpha)}
$$
となる。

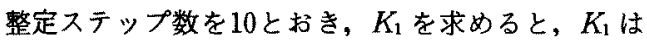

$$
\begin{aligned}
& K_{1}=\left[k_{0}, k_{1}, \cdots, k_{10}\right]\left[1, \lambda, \cdots, \lambda^{10}\right]^{r} \cdots \cdots \cdots(42) \\
& {\left[k_{0}, k_{1}, \cdots, k_{10}\right]} \\
& =[-0.792324,-1.256739,-1.474312 \\
& \quad-1.514654,-1.434792,-1.279291 \\
& -1.081210,-0.863534,-0.640857 \\
& \quad-0.421159,-0.207555]
\end{aligned}
$$

となる。

設計した系の感度特性は図 2 に示す。感度の周波数 特性から，低周波領域において，系の感度は低く抑え られており，しかも外乱の基本周波数およびその整数 倍の周波数における系の感度は 0 となっており，外乱 の影響は除去できることがわかる。

シミュレーションはパソコンを用いて行った。その 結果を図 3〜図 5 に示す。シミュレーションは基本的 に時間領域で行い，出力の回転速度を積分して得られ た角度情報を基準にして，角度依存性外乱を発生さ せ，「角度領域」での制御をシミュレートした。

図3では，ます，同図(a)のような基準目標入力 $\omega_{r}=20 \mathrm{rad} / \mathrm{s}$ をえ, 系が定常状態に入った後, $t=$ $1.36 \mathrm{~s}$ 加 ( a )図のような角度依存性外乱：

$$
\begin{aligned}
\nu(t) & =\tilde{v}\{\theta(t)\} \\
& =2 \sin \theta(t)+\sin 2 \theta(t)+0.5 \sin 3 \theta(t)
\end{aligned}
$$

が系に加ったとする。制御を施していない場合，（b) 図からも明らかに，この外乱が出力の回転速度に影響 を与え，回転速度には回転せらが生じていることがわ かる。

次に，制御を施した場合，同様に（b)図からも明ら かなように，出力は目標設定值に定常偏差なく追従

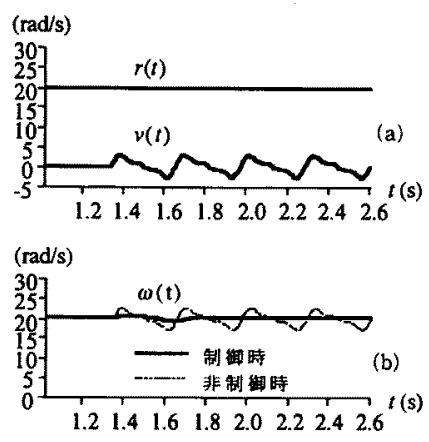

図 3 基準目標入力時の外乱応答

Fig. 3. Responses to the disturbance against the standard command input.
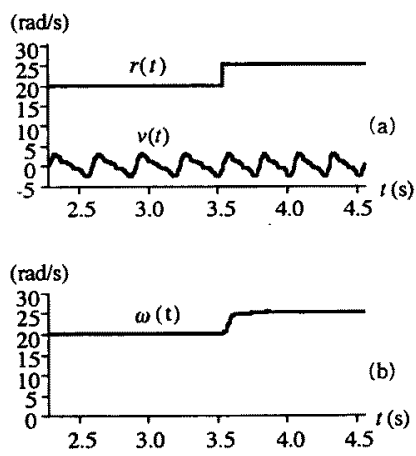

図 4 入力設定值の変化に対する応答 Fig. 4. Response to the change of the command input.
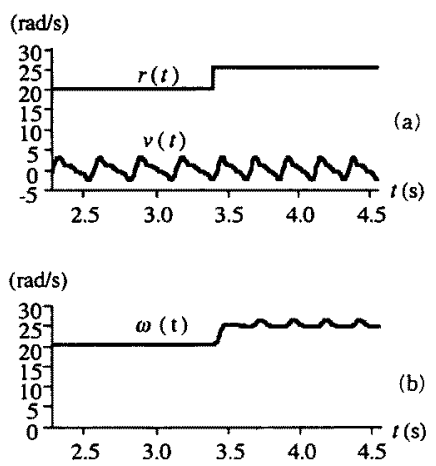

図 5 「時間領域」で設計した定速回転 制御系の応答

Fig. 5. Response of the constant speed rotation control system designed in the 'time domain'. 
し, 外乱の影響も二周期目から完全に除去されている ことがわかる。

図 4(a) では, $t=3.55 \mathrm{~s}$ の時点で目標設定值を 20 $\mathrm{rad} / \mathrm{s}$ から $25 \mathrm{rad} / \mathrm{s}$ に変えた場合, そのときの出力応 答を $(\mathrm{b})$ 図に示している。目標設定值が変えても, 出 カが入力に対して定常偏差なく追従し, 外乱の影響も 完全に除去できている。すなわち, 目標設定値が設計 值からずれても十分な制御効果が得られることがわか る。

ちなみに, 時間領域で繰返しコントローラを設計 し, 制御系を構成した。そのシミュレーション結果を 図 5 に示す。基準設定値の場合, 外乱の除去効果が良 いが, 設計值が変化すると, 外乱の除去効果は劣化す る〔( b )図〕ことが確認された。

\section{5. むすび}

本論文では, 回転系には回転むらの生じる原因とな る様々な外乱が回転角度に依存し, 回転角度の周期関 数となるという特徵に注目し,「角度領域」でこの問 題をとらえ, この種の外乱の除去について検討した。 すなわち,

（1）この種の外乱を「角度領域」で設計したコン トローラにより除去することを提案した。

（2）上の考え方を実現するための制御系の構成を 示し, その制御系の設計法を提案した。

（3）シミュレーションにより, 本設計法の有効性 を検証した。

最後に，本論文の作成にあたり御討論をいただいた 本学助手ビーチャイ氏に深く感謝の意を表す。

(平成 3 年 6 月 21 日受付)
(5) B. A. Francis: A Course in $H_{-}$Control Theory (1987) Springer-Verlag

(6) S. Hara \& T. Sugie : Independent Parameterization of Two-Degree- of-Freedom Compensators in General Robust Tracking Systems, IEEE Trans. Automatic Control AC-33 59/67 (1988)

（7）堀口・西村・長田・富田：「過渡応答を考慮した 2 自由度フ ッドピート制御」, 計測自動制御学論, 25, 1046 (平元-10)

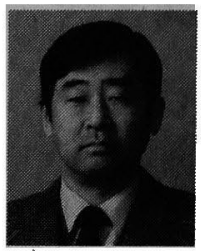

\section{中 野 道 雄（正員）}

昭和 14 年 2 月 17 日生。 43 年東京工 業大学大学院博士課程電気工学専攻修 了。同年同大学工学部助手, 48 年同助 教授，61 年同教授。 49 年より高エネル ギー物理学研究所併任。工学博士。計測制御機器, パワー エレクトロニクス系の制御に関する研究に従事。計測自動 制御学会, 日本シミュレーション学会, IEEE 会員。

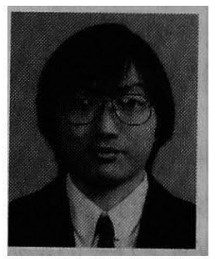

会錦 華 (准員)

1963 年 5 月 23 日生。1 1983 年 7 月中国 中南工業大学工業自動化学科卒業。 1990 年 3 月東京工業大学大学院理工学研究科 （制御工学専攻）博士前期課程修了。同 年 4 月同博士後期課程 (制御工学専攻) 入学, 現在に至 る。計測自動制御学会学生会員。

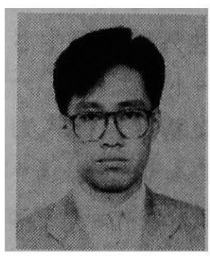
松 尾 芳 樹 (正員)

昭和 32 年 1 月 1 日生。 59 年 3 月東京 工業大学大学院博士課程制御工学尃攻修 了。同年 4 月同大学工学部助手, 平成 2 年 12 月ょり同助教授, 現在に至る。工

学博士。計測自動制御学会, IEEE 会員。
（1）後藤・小林：「直流モータのコギングトルクの解明と新しい 低隇方法」, 電学論 B, 103711 (昭 58-11)

（2）小林・原・田中・中野：「繰り返し制御を忍用したモー夕の 回転むら低減法」, 同上 D, 10729 (昭 62-1)

（3）中野・井上・山本・原：繰り返し制御（平元）計測自動制御 学会

(4) M. Vidyasager: Control System Synthesis: A Factorrization Approach (1985) MIT Press 